\title{
Study of a Pneumatic-electrical System for Exhaust Air Energy Recovery
}

\author{
Xing Luo ${ }^{1}$, Jihong Wang ${ }^{* 2}$, Hao Sun ${ }^{3}$ \\ ${ }^{1,2}$ School of Engineering, the University of Warwick, Coventry, CV4 7AL, UK \\ ${ }^{3}$ School of Electronic, Electrical and Computer Engineering, the University of Birmingham, Birmingham, B15 2TT, UK \\ 11xing.luo@warwick.ac.uk, *2jihong.wang@warwick.ac.uk; ${ }^{3}$ hxs823@bham.ac.uk
}

\begin{abstract}
In comparison to hydraulic and electrical actuators, the significant drawback of pneumatic actuators is low energy conversion ability which is due to the open-circuit structure in nature. This paper represents a hybrid pneumatic-electrical system for the purpose of recycling exhaust compressed air energy from existing pneumatic actuator outlets to generate electricity. A proper control strategy is developed to manage the actuator system operation and to ensure the energy recovery work well. The pneumaticelectrical system mathematical model and the simulation results are presented. The laboratory experimental tests are described. The system energy efficiency is also analyzed. The simulated and experimental studies demonstrate that the whole system operated by the designed controller can successfully recover exhaust compressed air energy under appropriate working conditions.
\end{abstract}

Keywords- Pneumatic Actuators; Electrical Systems; Energy Recovery; Mathematical Modelling; Process Control

\section{INTRODUCTION}

Compressed air, as a relatively clean and low-cost energy source, has been widely used in many application areas, especially in industry to generate driving forces for motions. From the statistics of the U.S. Department of Energy's Office of Energy Efficiency and Renewable Energy, in U.S., air compressors typically consume around $20 \%$ of electricity in manufacturing factories [1]. In China, pneumatic systems consume 10\%-20\% of the all electricity for factory operations, even reaching 35\% in some factories [2,3]. In Japan, compressed air systems expend 10\% 20\% of the total electricity usage in industrial plants, which can reach 40 billion kilowatt hours per year [4].

Pneumatic actuators use compressed air as the driving power to generate linear or angular motions. Resulting from pneumatic actuators' natural characteristics, for instance, relatively simple mechanical structure, stability in harsh operating conditions and low cost for manufacturing and maintenance, they are widely adopted in manufacturing, transportation and also people's daily life [5]. Nevertheless, it is reported that, in most cases, the energy efficiencies of pneumatic systems have around 23\%-30\% and sometimes even below 20\%, which are considerably lower than that of hydraulic and electrical counterparts $[4,6,7]$. The main reason for such low efficiency is the open-circuit structure of actuating systems $[8,9]$. The exhaust from pneumatic actuator outlets containing available compressed air energy directly discharges to the atmosphere.

For efficiency improvement, one idea can be thought of is to modify the air flow circuit at the discharging port for exhaust air energy recovery. This will require a mechanism connecting to the down-stream with relatively high energy efficiency. The scroll-type air motor technology attracts the authors' attention for this proposal mainly because of its own high energy conversion ability [9, 10], which inherited from the corresponding machinery, the scroll compressor [11]. Meanwhile, as the modification of the down-stream air circuit will affect the up-stream actuator's working conditions, an appropriate control strategy is indispensable to the whole system.

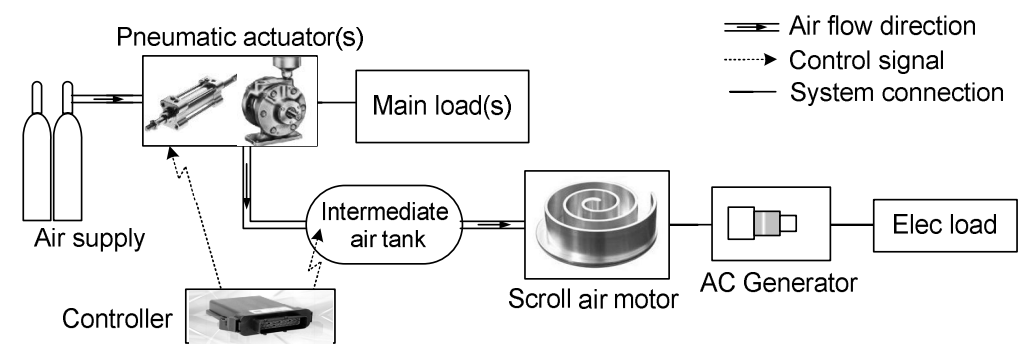

Fig. 1 Block diagram of the proposed pneumatic-electrical system

The proposed system structure is schematically shown in Fig. 1. The whole system can be considered to have several parts, as explained below:

1) Existing pneumatic actuator system: it serves as a simulation for actual industrial situations to produce the exhaust from pneumatic actuator(s), which is also named up-stream subsystem. This part consists of the air supply, the existing pneumatic actuator(s) and the main load(s).

2) Exhaust air energy recovery system: in this part, the exhaust air energy recycled by the scroll-type air motor converts 
to the electrical energy via the generator operation. The part is named down-stream subsystem in the paper as well. It includes an air tank, a scroll air motor, and an AC generator with its electric load. Employing an intermediate air tank is for weakening the negative effect from the down-stream to the up-stream and also for the control strategy implement.

3) Controller: a proper controller is developed for supporting the whole system operation. The controller manages the air flow and the air pressure at the up-stream and the down-stream.

\section{DESCRIPTION OF MATHEMATICAL MODEL OF THE PNEUMATIC-ELECTRICAL SYSTEM}

\section{A. Mathematical Model of a Vane-type Air Motor}

A vane-type air motor system is employed to mimic the existing pneumatic actuator system (up-stream subsystem) in this paper. In practice, the up-stream subsystem can be composed of one or more pneumatic actuators, which can be operating at the same time.

Fig. 2 shows the sketch of a vane-type air motor with four vanes. There is a rotational drive shaft with four slots, each of which is fitted with a sliding vane. And there are two ports connecting to the air motor chambers, which can be alternatively used as the inlet and the outlet. The air motor can be operated by employing two three-port valves or single five-port valve. Its working principle is: when the rotor is rotating, the vanes slide outward due to the centrifugal force and divide the air motor control volume into two chambers - driving and driven chambers; the driving force obtained from the compressed air pressure drives the rotor rotation with either clockwise or anticlockwise.

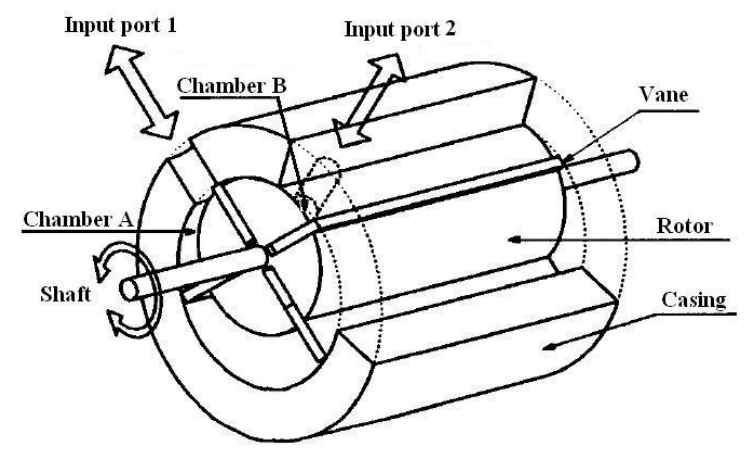

Fig. 2 Construction of a vane-type air motor with four vanes

A simplified structure of the vane-type air motor with eight vanes is shown in Fig. 3. From the authors' study, the dynamic responses are smoother when the number of vanes increases [12]. The control volumes of the vane-type air motor are described by (assuming Vane Chamber A and Vane Chamber B are the driving and the driven chambers respectively, see Fig. 3):

$$
\begin{aligned}
& V_{v_{-} a}=\frac{1}{2} L_{v}\left(B_{v}{ }^{2}-r_{v}{ }^{2}\right)\left[\pi+\left(\phi_{V}-i \frac{2 \pi}{N_{v}}\right)\right]+\frac{1}{4} L_{v} e_{v}{ }^{2} \sin 2\left(\phi_{v}-i \frac{2 \pi}{N_{v}}\right)+L_{v} B_{v} e_{v} \sin \left(\phi_{v}-i \frac{2 \pi}{N_{v}}\right)+\frac{1}{4} L_{v}\left[\frac{e_{v}{ }^{2}}{2} \sin \left(\frac{4 \pi}{N_{v}}\right)\right. \\
& \left.+2 e_{v} B_{v} \sin \left(\frac{2 \pi}{N_{v}}\right)+B_{v}{ }^{2}\left(\frac{2 \pi}{N_{v}}\right)-r_{v}{ }^{2}\left(\frac{2 \pi}{N_{v}}\right)\right] \times \operatorname{roundoff}\left[\frac{\left(\pi-2 \alpha_{v}\right)}{2 \pi / N_{v}}\right] \\
& V_{v_{-} b}=\frac{1}{2} L_{v}\left(B_{v}{ }^{2}-r_{v}{ }^{2}\right)\left[\pi-\left(\phi_{V}-i \frac{2 \pi}{N_{v}}\right)\right]-\frac{1}{4} L_{v} e_{v}{ }^{2} \sin 2\left(\phi_{v}-i \frac{2 \pi}{N_{v}}\right)-L_{v} B_{v} e_{v} \sin \left(\phi_{v}-i \frac{2 \pi}{N_{v}}\right)-\frac{1}{4} L_{v}\left[\frac{e_{v}{ }^{2}}{2} \sin \left(\frac{4 \pi}{N_{v}}\right)\right. \\
& \left.+2 e_{v} B_{v} \sin \left(\frac{2 \pi}{N_{v}}\right)+B_{v}{ }^{2}\left(\frac{2 \pi}{N_{v}}\right)-r_{v}{ }^{2}\left(\frac{2 \pi}{N_{v}}\right)\right] \times \text { roundoff }\left[\frac{\left(\pi-2 \alpha_{v}\right)}{2 \pi / N_{v}}\right]
\end{aligned}
$$

where $V$ is the volume in the air motor chambers, the subscripts $v_{-} a, v_{-} b$ stand for Vane Chamber A and Chamber B respectively, $e_{v}$ refers to the air motor eccentricity, $r_{v}$ stands for the actuator rotor radius, $B_{v}$ represents the radius of actuator body, $L_{v}$ stands for the vane active length, roundoff represents integer part of $\left[\left(\pi-2 \alpha_{v}\right) /\left(2 \pi / N_{v}\right)\right], N_{v}$ is the number of vanes, $i$ is an arbitrary integer. The mathematical model for the vane-type air motor with arbitrary $N$ vanes can be derived (for details, please refer to [12]):

$$
\begin{gathered}
\dot{P}_{v_{-} a}=\frac{\gamma R T_{s} C_{d} C_{0} D_{v_{-} a} u_{1} \times f\left(P_{v_{-} a}, P_{s}, P_{e}\right)}{V_{v_{-} a} \phi_{V}}-\frac{\gamma}{V_{v_{-} a} \phi_{V}}+\frac{d V_{v_{-} a}}{d \phi_{V}} \phi_{V} P_{v_{-} a} \omega_{V} \\
\dot{P}_{v_{-} b}=\frac{\gamma R T_{s} C_{d} C_{0} D_{v_{-} b} u_{2} \times f\left(\dot{P}_{v_{-} b}, P_{s}, P_{e}\right)}{V_{v_{-} b} \phi_{V}}-\frac{\gamma}{V_{v_{-} b} \phi_{V}}+\frac{d V_{v_{-} b}}{d \phi_{V}} \phi_{V} \dot{P}_{v_{-} b} \omega_{V}
\end{gathered}
$$




$$
\dot{\omega}_{V}=\frac{L_{v}}{2 J_{V}}\left(P_{v_{-} a}-P_{v_{-} b}\right) \times\left(e_{v}^{2} \cos 2 \phi_{V}+2 e_{v} B_{v} \cos \phi_{V}+B_{v}^{2}-r_{v}^{2}\right)-\frac{K_{c v}}{J_{V}} S\left(\omega_{V}\right)-\frac{K_{f v}}{J_{V}} \omega_{V}
$$

where $\omega_{V}$ stands for the vane air motor speed, $\phi_{V}$ represents the vane air motor rotor position, $P_{v_{-} a}, P_{v_{-} b}$ stand for the vane air motor chamber pressures, $u_{1}$ and $u_{2}$ are the spool valve opening displacements, $D$ stands for the control valve port width, $J_{v}$ stands for the vane air motor inertia, $K_{f v}$ and $K_{c v}$ represent the vane air motor dynamic and static frictional coefficients respectively, $P_{s}, P_{e}$ stand for supply and exhaust pressures, $C_{d}$ and $C_{0}$ are the discharge coefficient and the flow constant, $i$ is an arbitrary integer, $\gamma$ is the specific heat ratio of air, $R$ stands for universal gas constant. The values of constants appear in the model $\left(\gamma, C_{0}, C_{d}, R\right)$ and the functions of $f(\cdot)$ and $S(\cdot)$ are given in [12].

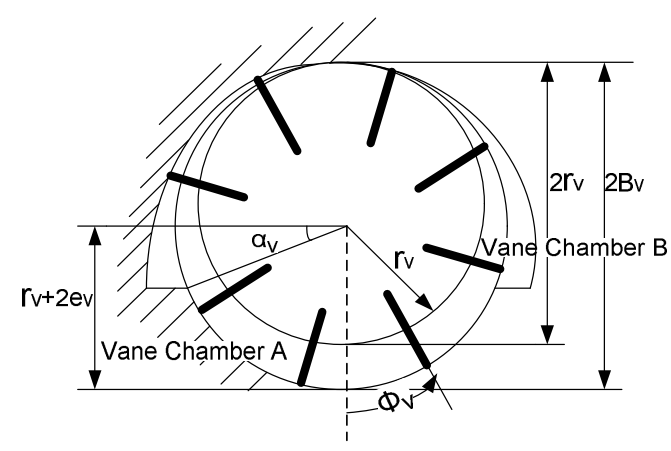

Fig. 3 Structure of a vane-type air motor with eight vanes

\section{B. Mathematical Model of a Scroll-type Air Motor}

A scroll-type air motor, also named a scroll expander, is a relatively new technology to pneumatic actuators. According to its high energy efficiency characteristics, it has been chosen as the core of the exhaust air energy recovery system. Its working principle can be considered as a refrigeration scroll compressor working backwards. A scroll air motor in motion is illustrated in Fig. 4. There are two scrolls: the black stands for the moving scroll and the grey represents the fixed scroll. The moving scroll shifts along with the circular orbit in anticlockwise. These two scrolls keep touching at some points during the air motor operation, and the even number of sealed crescent chambers is generated. This smart structure leads to the scroll many strengths as well as higher ability of energy conversion than traditional pneumatic actuators, such as cylinders, vane-type air motors, etc. $[10,11,13]$.

A scroll-type air motor working process includes three phases: charging phase, expansion phase and discharging phase, which correspond to the central chamber, the side chamber and the exhaust chamber [13]. During the air motor operation, the compressed air energy in chambers pushes and drives the moving scroll shift to rotate the crank, and the air energy converts to the mechanical kinetic energy of the air motor shaft (see Fig. 4).

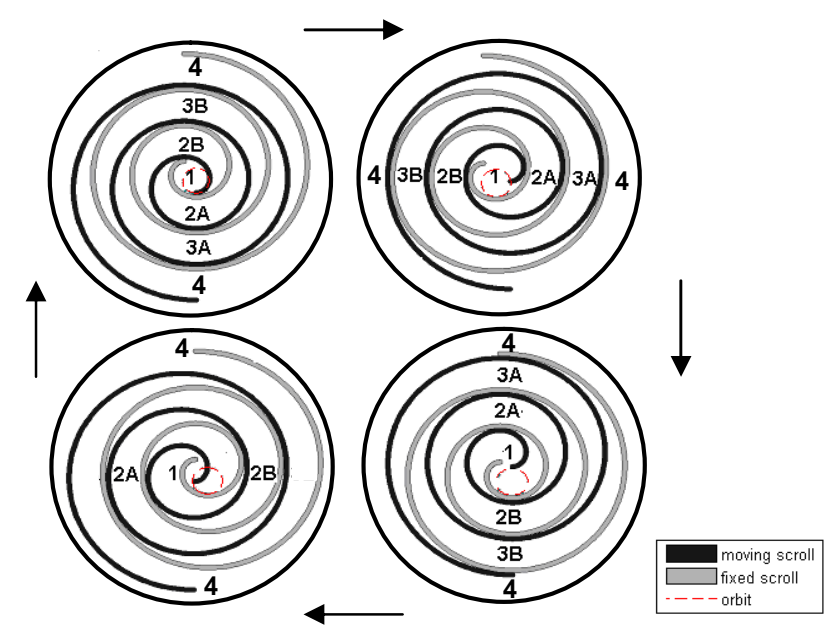

Fig. 4 Schematic diagram of a scroll-type air motor

To obtain a mathematical model of a scroll air motor, the geometry features have been firstly studied. The scroll geometric model can be derived from the fundamental curve of a spiral. From the study, the equations for the moving scroll can be described by, 


$$
\begin{aligned}
& x_{\mathbf{A}}\left(\varphi_{s}, \alpha_{s}\right)=x_{0}+\left(\rho_{0}+\kappa_{s} \varphi_{s}\right) \sin \varphi_{s}+\kappa_{s} \cos \varphi_{s}-\kappa_{s}+r_{s} \sin \alpha_{s} \\
& y_{\mathbf{A}}\left(\varphi_{s}, \alpha_{s}\right)=y_{0}-\left(\rho_{0}+\kappa_{s} \varphi_{s}\right) \cos \varphi_{s}+\kappa_{s} \sin \varphi_{s}+\rho_{0}-r_{s} \cos \alpha_{s}
\end{aligned}
$$

where $\rho_{0}$ stands for the initial curvature radius for the scroll curve, $\kappa_{s}$ represents the slope of the curvature radius, $r_{s}$ refers to the orbit radius of the moving scroll, $\alpha_{s}$ stands for the scroll orbit angle, $\varphi_{s}$ is the tangential angle corresponding to the moving scroll.

The fixed scroll is formed by the curve which envelops the family of the moving scroll curves while the moving scroll wobbles inside the air motor and moves along with its orbit [9]. Thus the equations for the fixed scroll can be obtained,

$$
\begin{aligned}
& x_{\mathbf{B}}\left(\phi_{s}+j \pi\right)=x_{0}+\left(\rho_{0}+\kappa_{s}\left(\phi_{s}+j \pi\right)\right) \sin \left(\phi_{s}+j \pi\right)+\kappa_{s} \cos \left(\phi_{s}+j \pi\right)-\kappa_{s}+r_{s} \sin \left(\phi_{s}+j \pi\right) \\
& y_{\mathbf{B}}\left(\phi_{s}+j \pi\right)=y_{0}-\left(\rho_{0}+\kappa_{s}\left(\phi_{s}+j \pi\right)\right) \cos \left(\phi_{s}+j \pi\right)+\kappa_{s} \sin \left(\phi_{s}+j \pi\right)+\rho_{0}-r_{s} \cos \left(\phi_{s}+j \pi\right)
\end{aligned}
$$

where $\phi_{s}$ is the tangential angle corresponding to the fixed scroll, $j$ is an arbitrary integer. The moving scroll contacts the fixed scroll at the points, $\varphi_{s}=\phi_{s}+j \pi$.

Applying Green's Theorem, the equations for describing the volume variations of the scroll central chamber is derived [9],

$$
\begin{aligned}
V_{s_{-} c}\left(\alpha_{s}\right)= & z\left[\left(x_{0} \kappa_{s} \pi-\kappa_{s}{ }^{2} \pi-x_{0} r_{s}+r_{s} \kappa_{s}\right) \cos \alpha_{s}+\kappa_{s}{ }^{2} \pi \alpha_{s}{ }^{2}+\left(r_{s} \rho_{0} \kappa_{s} \pi-r_{s} \rho_{0}-y_{0} r_{s}+y_{0} \kappa_{s} \pi\right) \sin \alpha_{s}-r_{s} \kappa_{s}\right. \\
& \left.+\frac{1}{3} \kappa_{s}{ }^{2} \pi^{3}+\left(r_{s} \pi \kappa_{s}+2 \kappa_{s} \rho_{0} \pi\right) \alpha_{s}-\frac{1}{2} r_{s} \pi^{2} \kappa_{s}+\rho_{0} r_{s} \pi+\frac{1}{2} r_{s}{ }^{2} \pi+\rho_{0}^{2} \pi\right]
\end{aligned}
$$

where $V_{s_{-} c}$ stands for the scroll central chamber volume, $z$ is the depth of the moving and fixed scrolls.

The control volume of the $i^{t h}(i=1,2,3 \ldots)$ pair of side chambers is:

$$
V_{s_{-} s}\left(\alpha_{s}, i\right)=z\left[\pi r_{s}^{2}+2 \pi r_{s}\left(\rho_{0}+\kappa_{s}\left(\alpha_{s}+\pi+2(i-1) \pi\right)\right)\right]
$$

where $V_{s_{-} s}$ refers to the scroll side chamber volume.

The control volume of the scroll exhaust chamber can be described by,

$$
V_{s_{-} e}\left(\alpha_{s}\right)=V_{s t o l}-V_{s_{-} c}\left(\alpha_{s}\right)-\sum V_{s_{-} s}\left(\alpha_{s}, i\right)
$$

where $V_{s_{-} e}$ refers to the scroll exhaust chamber volume, $V_{\text {stol }}$ represents the total control volume of the scroll air motor.

Applying the thermodynamic theory and considering the air leakage effect, a complete thermodynamic model for the scroll-type air motor can be described (for details, refer to $[9,13]$ ).

For the scroll air motor central chamber,

$$
\begin{gathered}
\dot{T}_{s_{-} c}=\frac{1}{\left[X_{\text {air }}\right] C_{p, a i r}\left(T_{s_{-} c}\right)-P_{s_{-} c} / T_{s_{-} c}}\left\{\frac{\dot{m}_{i n} h_{i n}}{V_{s_{-} c}}-\frac{\dot{m}_{\text {leakc }} s h_{s_{-} c}}{V_{s_{-} c}}-\frac{\dot{V}_{s_{-} c}}{V_{s_{-} c}}\left[X_{a i r}\right] \hat{h}_{s_{-} c}-\left[\dot{X}_{\text {air }}\right] \hat{h}_{s_{-} c}+\frac{P_{s_{-} c}\left[\dot{X}_{a i r}\right]}{\left[X_{a i r}\right]}\right\} \\
\dot{P}_{s_{-} c}=\frac{1}{V_{s_{-} c}}\left(\frac{\dot{m}_{s_{-} c}}{M_{\text {air }}} R T_{s_{-} c}+R \dot{T}_{s_{-} c} \frac{m_{s_{-} c}}{M_{\text {air }}}-P_{s_{-} c} \dot{V}_{s_{-} c}\right)
\end{gathered}
$$

For the scroll air motor side chambers,

$$
\begin{gathered}
\dot{T}_{s_{-} s}=\frac{1}{\left[X_{\text {air }}\right] C_{p, a i r}\left(T_{s_{-} s}\right)-P_{s_{-} s} / T_{s_{-} s}}\left\{\frac{\dot{m}_{\text {leakc } s} h_{s_{-} c}}{V_{s}}-\frac{\dot{m}_{\text {leaks } e} h_{s_{-} s}}{V_{s}}-\frac{\dot{V}_{s_{-} s}}{V_{s_{-} s}}\left[X_{\text {air }}\right] \hat{h}_{s_{-} s}-\left[\dot{X}_{\text {air }}\right] \hat{h}_{s_{-} s}+\frac{P_{s_{-} s}\left[\dot{X}_{\text {air }}\right]}{\left[X_{\text {air }}\right]}\right\} \\
\dot{P}_{s_{-} s}=\frac{1}{V_{s_{-} s}}\left(\frac{\dot{m}_{s_{-} s}}{M_{\text {air }}} R T_{s_{-} s}+R \dot{T}_{s_{-} s} \frac{m_{s_{-} s}}{M_{\text {air }}}-P_{s_{-} s} \dot{V}_{s_{-} s}\right)
\end{gathered}
$$

For the scroll air motor exhaust chamber,

$$
\dot{T}_{s_{-} e}=\frac{1}{\left[X_{\text {air }}\right] C_{p, a i r}\left(T_{s_{-} e}\right)-P_{s_{-} e} / T_{s_{-} e}}\left\{\frac{\dot{m}_{\text {leaks } e} h_{s_{-} s}}{V_{s_{-} e}}-\frac{\dot{m}_{\text {out }} h_{s_{-} e}}{V_{s_{-} e}}-\frac{\dot{V}_{s_{-} e}}{V_{s_{-} e}}\left[X_{\text {air }}\right] \hat{h}_{s_{-} e}-\left[\dot{X}_{\text {air }}\right] \hat{h}_{s_{-} e}+\frac{P_{s_{-} e}\left[\dot{X}_{\text {air }}\right]}{\left[X_{\text {air }}\right]}\right\}
$$




$$
\dot{P}_{s_{-} e}=\frac{1}{V_{s_{-} e}}\left(\frac{\dot{m}_{s_{-} e}}{M_{\text {air }}} R T_{s_{-} e}+R \dot{T}_{s_{-} e} \frac{m_{s_{-} e}}{M_{\text {air }}}-P_{s_{-} e} \dot{V}_{s_{-} e}\right)
$$

For the rotor acceleration of the scroll air motor,

$$
\dot{\omega}_{s}=\sum_{n=0,1,2, \ldots} \frac{1}{J_{s}}\left[-K_{f s} \omega_{s}+z r_{s} \hat{P}\left(2 \rho_{0}+2 \kappa_{s} \alpha_{s}+\left(4 n_{s}+1\right) \kappa_{s} \pi\right)\right]
$$

where the subscripts in, out refer to air input and out respectively; the subscripts $s_{-} c, s_{-} s, s_{-} e$ represent the central, side and exhaust chambers respectively; $P$ refers to the air pressure; $T$ represents temperature; $V$ stands for volume; $\dot{m}$ is mass flow rate; $M_{a i r}$ refers to the molar mass of air; $\left[X_{\text {air }}\right]$ is the molar volumetric concentration of air; $h$ is the enthalpy of air; $\hat{h}$ is the specific enthalpy of air on a molar basis; $C_{p, a i r}(T)$ is the air specific heat per mole at the temperature $T ; \omega_{s}$ represents the scroll rotor angular speed; $J_{s}$ stands for the scroll air motor inertia, $K_{f s}$ refers to the kinematic friction coefficient, $\dot{m}_{l e a k c_{-} s}$ stands for the air leakage mass flow rate from the central chamber to the side chamber, $\dot{m}_{l e a k s_{-} e}$ stands for the air leakage mass flow rate from the side chambers to the exhaust chamber.

In the designed system, a permanent magnet synchronous generator (PMSG) has been employed as the load of the scroll air motor for the simulation study and the experimental test system because of its own simple structure [14]. The employed mathematical model of PMSG was reported in [15-17, 25].

Integrating all above equations, the whole system model can be derived. Due to the limitation of pages, it is impossible to give the details for the mathematical model of each subsystem. They can be found in the reference list $[9,12,13,17]$.

\section{CONTROL STRATEGY DEVELOPMENT}

Based on the subsystem models presented in Section II, the pneumatic-electrical system model (refer to Fig. 1) is built in Matlab/Simulink environment for simulation study. The simulation study of the non-controlled pneumatic-electrical system had been implemented. The simulation was organized as follows: the exhaust energy recovery system was activated after the up-stream vane air motor system had been in motion at the steady state. From the simulation results, it is found that the exhaust pressure from the up-stream subsystem raises and the vane-type air motor rotor speed drops, which means the working condition of the up-stream subsystem is varied. Thus, it is essential to develop an appropriate control strategy to the overall pneumatic-electrical system.

According to the above study, a closed-loop control must be introduced to the designed system. It needs to manage the overall system to maintain the up-stream operation status and to ensure the down-stream scroll recycling work simultaneously. A combination of a PID and an On/Off control is employed to the system as shown in Fig. 5. Two controllers are used: one On/Off controller associated with an on/off valve is to keep the pressure inside the air tank at a certain level for reducing the down-stream negative effect; one PID controller imposed onto a proportional valve is to regulate the whole system air flow and to keep the speeds of the up-stream actuator' motion.



Fig. 5 Schematic of the control system

Fig. 6 shows the simulation results of dynamic responses of the controlled overall pneumatic-electrical system for recycling the up-stream vane air motor exhaust energy, which include the vane air motor rotor angular speed, the air motor rotor angular position and the pressure inside the air tank variation histories. The simulation was conducted by activating the down-stream energy recovery system at 1.5 seconds of the simulation time. The vane-type air motor rotation angles and the rotating speeds in two situations were presented respectively, i.e., with and without engaging the recycling mechanism. From Fig. 6, it is shown that the pressures of the intermediate air tank are limited to have the range of $P_{\max }=2.6 \times 10^{5} P a$, i.e., when the tank pressure is higher than $2.6 \times 10^{5} \mathrm{~Pa}$, the on/off valve for the tank is fully open to release the air; and $P_{\min }=2.3 \times 10^{5} P a$, the valve is completely closed while the tank pressure is lower than $2.3 \times 10^{5} \mathrm{~Pa}$. From the simulation study, with the controllers for the two valves in action, the up-stream movement can be approximately maintained and the energy recycling system also works well. The whole system energy recovery ability will be analysed in the last section of the paper. 

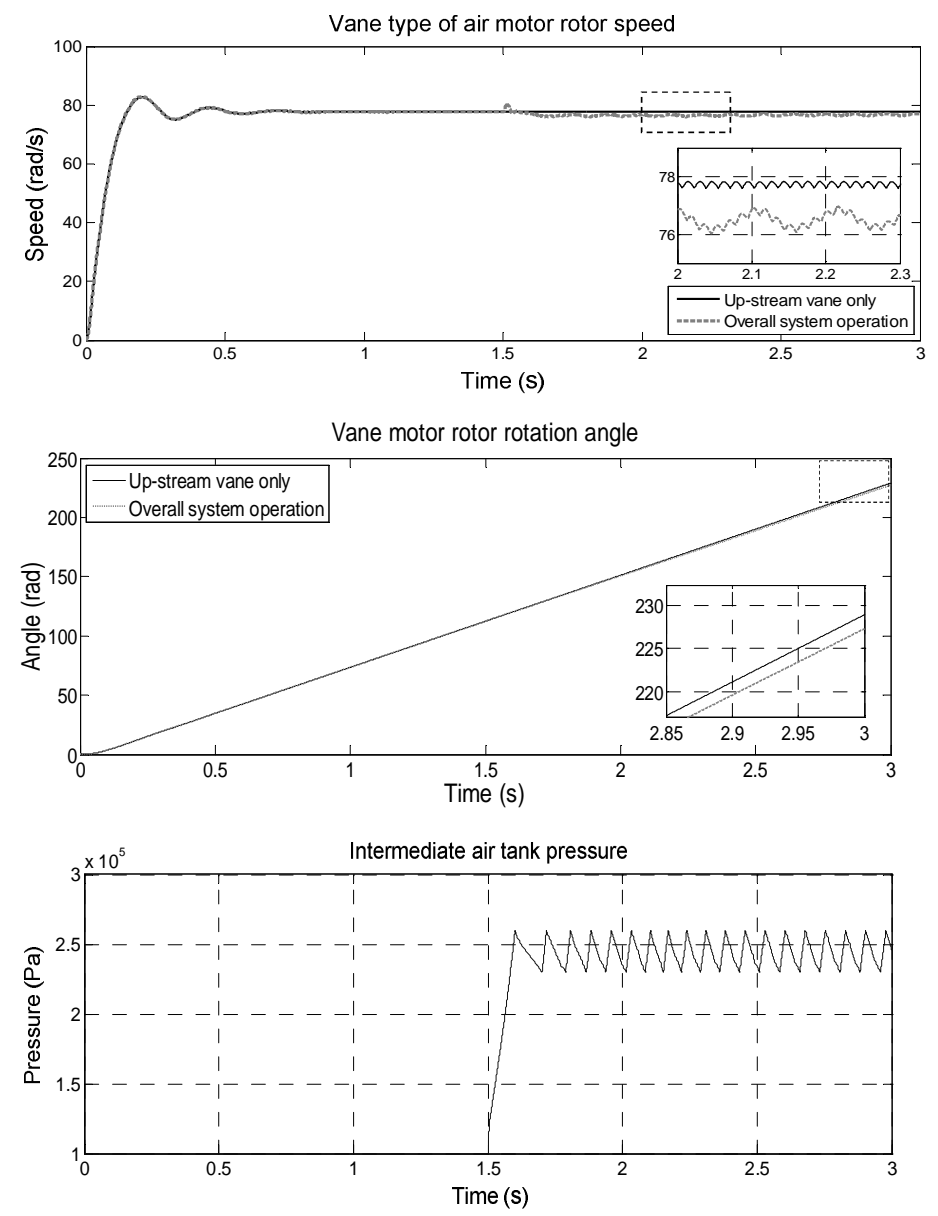

Fig. 6 Dynamic response of the overall pneumatic-electrical system with the designed controller operation

\section{IV.EXPERIMENTAL TESTS}

\section{A. Experimental Tests for Model Validation}

The scroll-type air motor model had been validated in the authors' previous work (for details, refer to [13]). Thus, the experimental test rig for the vane-type air motor model validation is set up accordingly. It consists of a vane-type air motor with eight vanes, a DC generator and its electrical resistance load (refer to Table 1). Compared to the test rig for the scroll air motor model validation described in [13], the vane-type air motor instead of the scroll-type air motor drives the DC generator with its resistance load for the validation work. The mathematical model equations for the DC generator and the load are given in [13].

Fig. 7 illustrates the comparison of experimental and simulation results for the vane-type motor rotor speed and the generator current respectively. It can be seen that the simulated results agree with the measured results well. Thus the mathematical model for the vane-type air motor can represent the dynamic features of vane-type air motors.

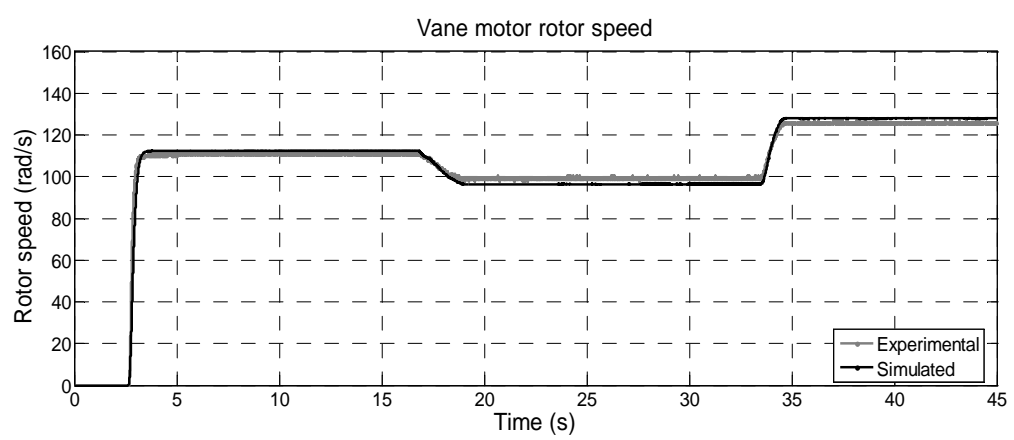






Fig. 7 Comparison of simulated and experimental results for vane-type air motor model validation

\section{B. Experimental Tests for the Pneumatic-electrical System}

The pneumatic-electrical system test rig had been set up at the authors' research laboratory in the University of Birmingham. It is used for implementing the process from an up-stream vane-type air motor system to the exhaust air recycling mechanism, which is shown in Fig. 8. A dSPACE controller card (Model: RTI1104) is chosen for the data acquisition from sensors and the pneumatic valves' control. The system components for machines are listed in Table 1.

TABLE 1 MACHINES FOR THE PNEUMATIC-ELECTRICAL EXPERIMENTAL TEST SYSTEM

\begin{tabular}{lll}
\hline Components & Serial number & Manufacturer \\
\hline Vane-type air motor & 8AM-FRV & Gast \\
DC generator & M4-2005N-0000Y -111 & Callan Technology \\
Intermediate air tank & Made by Profile 8 80×80 & Item \\
Scroll-type air motor & Modified from TRSA05 & Sanden \\
PMSG Generator & 3BRS 71-M4-3000 & Motor Technology \\
\hline
\end{tabular}

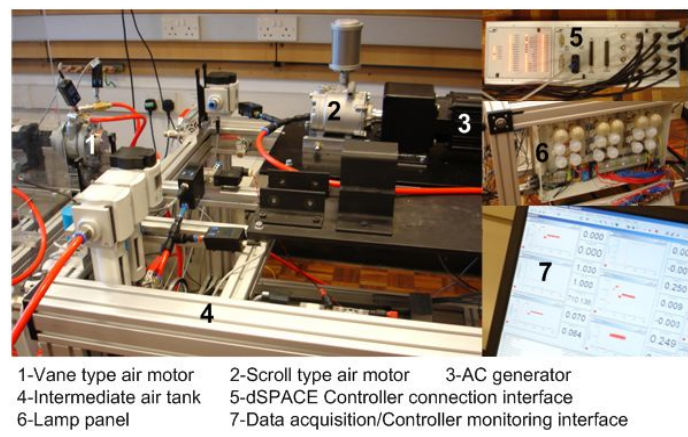

Fig. 8 The pneumatic-electrical experimental test system

The majority parameters of the generators are available in the associated handbooks $[18,19]$. The unknown parameters can be identified using intelligent optimization algorithms with the experimental data [20]. One proportional pneumatic valve is used to control the air input to the whole system. One On/Off pneumatic valve is used to control the intermediate air tank pressure.

To analyze the down-stream negative effect and the non-controlled system, the term of the vane-type air motor speed rate $\left(\lambda_{V}\right)$ is defined in the experimental test studies for observing the vane-type air motor movement variation and the side-effect imposed onto the up-stream actuator operation:

$$
\lambda_{V}=\frac{\dot{\phi}_{V}\left(P_{\text {down }}=P_{e n}\right)}{\dot{\phi}_{V}\left(P_{\text {down }}=P_{\text {atm }}\right)}
$$

where $\dot{\phi}_{V}\left(P_{\text {down }}=P_{\text {atm }}\right)$ stands for the vane-type air motor speed when its down-stream pressure is at the atmosphere pressure and $\dot{\phi}_{V}\left(P_{d o w n}=P_{e n}\right)$ refers to the speed while the down-stream pressure is at the level of $P_{e n}$. These two speeds are obtained at the same compressed air supply conditions. And the pressure $\left(P_{e n}\right)$ has been controlled by the air tank connected to the vanetype air motor outlet. Thus, the higher speed rate $\left(\lambda_{V}\right)$ means the less side-effect imposed.

Fig. 9 shows the vane-type air motor speed rate variation at different air supply pressures with a fixed down-stream pressure $\left(P_{e n}\right)$ at $2.5 \times 10^{5} \mathrm{~Pa}$ and the variations of the proportional flow control valve port opening. It can be seen that, from the 
experiments, at the low supply pressure, the larger valve opening will lead to the bigger speed rate changes. Also it can be seen that, in some situations, the speed rate can be higher than $80 \%$ when the supply pressure is higher than $6.0 \times 10^{5} \mathrm{~Pa}$. It may indicate that the side-effect caused by connecting the down-stream recovering system can be reduced by working at relatively high supply air pressures under appropriate working conditions. Also from our study, the selection of the intermediate air tank dimension is an important factor to reduce this effect.

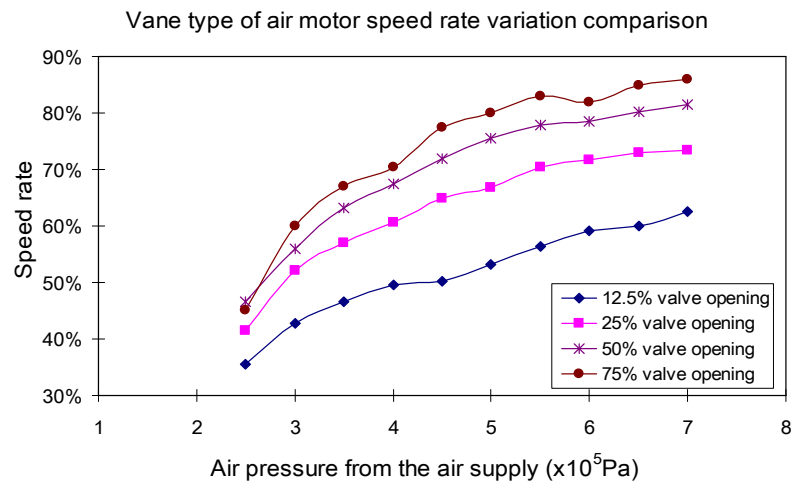

Fig. 9 Experimental results of the vane-type air motor speed rate variation

Fig. 10 shows the experimental results of the controlled pneumatic-electrical system, which include the control signal of the On/Off valve, the vane-type air motor rotor speed and the PMSG line voltage. The system sampling time sets at $0.01 \mathrm{~s}$. The pressure from the cylinder as the air supply is set to be $5.6 \times 10^{5} \mathrm{~Pa}$ (see Fig. 1). The 3-phase electric load for the PMSG uses a lamp panel (see Fig. 9). The recycling system is activated at the $13^{\text {th }}$ second when the up-stream vane-type air motor starts its operation. The pressure of the air tank is limited within the range of $P_{\max }=2.6 \times 10^{5} \mathrm{~Pa}$ and $P_{\min }=2.3 \times 10^{5} \mathrm{~Pa}$. From the experimental tests, it is found that scroll-type air motor intake pressure has a slight oscillation due to the On/Off valve operation. Also from Fig. 10, it is noticed that the speed of the up-stream actuator is less smooth than the speed while no recovering mechanism is involved. This can be improved by applying a strengthened speed controller which is considered as one of the tasks in the next stage of the research work. Through repeated experimental tests, the overall test system can work well in a certain range depending on the reasonable settings of the pressure limits of intermediate air tank.
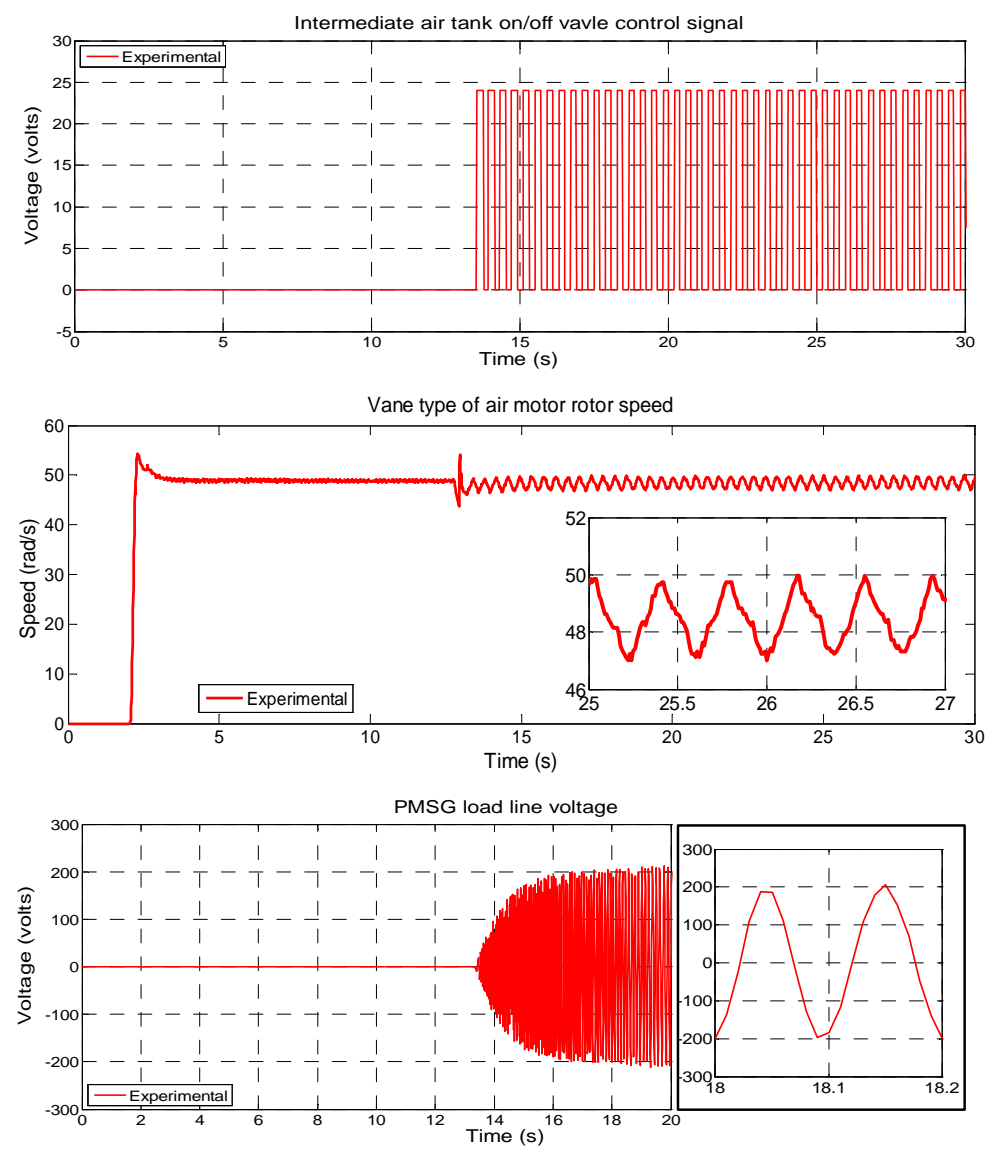

Fig. 10 Experimental results of the overall pneumatic-electrical system with designed controller operation 


\section{Experimental Tests for Exhaust Energy Recovery Analysis}

After studying the dynamic responses of the proposed pneumatic-electrical system, we need to further analyze the system energy efficiency to prove that the designed system can recover the exhaust air energy.

For analysing the system energy efficiency, it is necessary to study the compressed air energy/power firstly. The composition of air power consists of the transmission air power and the expansion air power [4]. The scroll-type air motor can employ these two air powers inside its air motor chambers $[10,13]$. This is one of the key reasons why the scroll air motor owns the high energy conversion ability.

From the above study, it is essential to find out how much air energy/power enters to the pneumatic-electric system, which is defined as the system input energy/power. One method for calculating the air power at a given state referred to the air power at STP $\left(0^{\circ} \mathrm{C}\right.$ at $\left.1 \mathrm{~atm}\right)$ can be expressed by a function of the corresponding air pressure and temperature $[3,22,24]$,

$$
\dot{W}_{a i r}=\dot{m} R T_{a t m} \ln \frac{P}{P_{a t m}}+\frac{\dot{m} R T_{a t m} \gamma}{\gamma-1}\left(\frac{T}{T_{a t m}}-1-\ln \frac{T}{T_{a t m}}\right)
$$

where $\dot{W}_{\text {air }}$ stands for the air power, the subscript atm represents the atmosphere, $\gamma$ stands for the air specific heat ratio, $R$ is the gas constant of air, $\dot{m}$ refers to the mass flow rate, $T$ and $P$ stand for the temperature and the pressure at the given state respectively. From the previous research, it has been found that, the change of air power is below $15 \%$ when air temperature shifts $100 \mathrm{~K}$ from the atmospheric temperature [21,22]. Thus, if do not consider temperature variations, $T=T_{a t m}$, then Eq. (21) can be simplified [4, 22],

$$
\dot{W}_{\text {air }}=\dot{m} R T_{a t m} \ln \frac{P}{P_{a t m}}
$$

When the existing pneumatic actuator system is in motion only, the system energy efficiency can be calculated by:

$$
\eta_{\text {existing }}=\frac{\dot{W}_{\text {actuator_power }}}{\dot{W}_{\text {input }}}
$$

where $\dot{W}_{\text {actuator } \_ \text {power }}$ refers to the existing pneumatic actuator useful output power, i.e., the main load power; $\dot{W}_{\text {input }}$ stands for the input air power to the whole system, which can be calculated by Eq. (21) and Eq. (22) at the compressed air supply states.

When the overall pneumatic-electrical system is in motion, the definition of the overall system energy efficiency used in the paper is:

$$
\eta_{\text {overall }}=\frac{\dot{W}_{\text {actuator_power }}+\dot{W}_{\text {recycle_power }}}{\dot{W}_{\text {input }}}
$$

where $\dot{W}_{\text {recycle_power }}$ is the exhaust air energy recovery power obtained by the scroll air motor and the PMSG's operation, which refers to the 3-phase electrical load power to the built test rig. To the experimental tests, if the up-stream vane-type air motor average speeds are kept above $90 \%$ of its desired speeds, the vane-type air motor movement is considered to be maintained in the system energy efficiency analysis. Thus, the relative difference ratio $(\lambda)$ to represent the designed pneumatic-electrical system energy recovery ability can be defined as,

$$
\lambda=\frac{\eta_{\text {overall }}-\eta_{\text {existing }}}{\eta_{\text {existing }}} \times 100 \%
$$

To the assembled test rig (see Fig. 8), the experimental tests to the calculation of the exhaust air energy recovery ability had been conducted. The pressure limitations of the intermediate air tank are set at $P_{\max }=2.5 \times 10^{5} \mathrm{~Pa}, P_{\min }=2.3 \times 10^{5} \mathrm{~Pa}$. The experimental results of the energy efficiency for the vane air motor system with and without engaging the exhaust recycling mechanism at different supply pressures have been compared.

In the tests, it is noticed that the overall pneumatic-electrical system can work properly in a certain range of pressures from the air supply (see Fig. 1), from $3.5 \times 10^{5} \mathrm{~Pa}$ to $6.4 \times 10^{5} \mathrm{~Pa}$. The working starting point $\left(3.5 \times 10^{5} \mathrm{~Pa}\right)$ is the operation point for engaging the recycling scroll-type air motor and the down-stream energy recovery system can run reliably from this point. And the working ending point $\left(6.4 \times 10^{5} \mathrm{~Pa}\right.$. $)$ is the operation point for isolating the exhaust air recycling system. It may be difficult to effectively control the whole system and recover the energy while the pressure is higher than the working ending point. 
According the experimental tests, the energy recovery ratio has been initially calculated. It is found that, with the same supply pressures, compared to the energy efficiency of the up-stream vane-type air motor, the exhaust energy recovery ratio can be obtained from $7.2 \%$ to $15.3 \%$ in the range of the supply air pressures from $3.5 \times 10^{5} \mathrm{~Pa}$ to $6.4 \times 10^{5} \mathrm{~Pa}$. Thus, the designed pneumatic-electrical system can recycle the exhaust air energy indeed. Further improvement of the ability of exhaust air energy recovery can be achieved by applying an advanced controller to the whole system; reducing the system air leakage and restructuring the system structure with optimal connections and design, which are considered as the next steps for the research work.

\section{CONCLUSIONS}

The paper represents the work on the development of a novel pneumatic-electrical system for exhaust compressed air energy recycling from the traditional pneumatic actuator systems. An integrated process mathematical model for the whole pneumatic-electrical system is derived. A proper control strategy for the system is developed. The simulation study provided fundamental understanding to the system. A laboratory experimental test system is built and then tested with the designed controller. The side-effect from the down-stream connection has been analysed. From the study, it can be concluded that the overall system energy efficiency can be improved and the exhaust air energy from pneumatic actuators can be recovered. The further research work for improving the pneumatic-electrical system ability of exhaust air energy recovery mentioned in Section IV is on-going.

\section{ACKNOWLEDGEMENT}

The authors would like to thank the grant support from EPSRC (GR/H004084), Advantage West Midlands and the European Regional Development Agency for the support of Birmingham Science City Energy Efficiency \& Demand Reduction project.

\section{REFERENCES}

[1] (2010) The Energy Resources Center of the Illinois Industries of the Future. [Online]. Available: http://www.erc.uic.edu/ iof/comp_air.html.

[2] (2009) Energy Conservation and Environment Protection Center and SMC Corporation, Beijing University of Aeronautics \& Astronautics. [Online]. Available: http://www.c-cnc.com/ news/ news.asp?id=43354.

[3] M.L. Cai, and T. Kagawa, "Energy consumption assessment and energy loss analysis in pneumatic system", Chinese Journal of Mechanical Engineering, vol.43, iss.9, pp.69-74, 2007.

[4] M.L. Cai, K. Kawashima, and T. Kagawa, "Power assessment of flowing compressed air", Journal of Fluids Engineering, vol. 128, pp. 402-405, 2006.

[5] P. Andrew, Hydraulics and Pneumatics: A Technician's and Engineer's Guide, Oxford, U.K.: Butterworth Heinemann, pp. 3-25, 1998.

[6] G. Belforte, New developments and new trends in pneumatics, keynote lecture of FLUCOME 2000, in the 6th International Symposium on Flow Control, Measurements and Flow Visualization, Canada, 2000.

[7] T. Kagawa, M.L. Cai, T. Fujita, and M. Takeuchi, "Energy consideration of pneumatic cylinder actuating system", in Proc. of the 6th Triennial International Symposium on Fluid Control, Measurement and Visualization, Sherbrooke, Canada, 2000.

[8] S. R. Majumdar, Pneumatic Systems: Principles and Maintenance, Tata McGraw-Hill, pp.1-33, 1996.

[9] J. Wang, L. Yang, X. Luo, S. Mangan, and J.W. Derby, "Mathematical modelling study of scroll air motors and energy efficiency analysis - Part I", IEEE/ASME Trans. on Mechatronics, vol. 16, pp. 112-121, 2011.

[10] T. Yanagisawa, "Performance of an oil-free scroll-type expander", Technical report, Institution of Mechanical Engineers, Fluid Machinery Group, Institution of Mechanical Engineers, City University, London, 2003.

[11] Y. Chen, N. Halm, E. Groll, and J. Braun, "Mathematical modelling of scroll compressors—part I: compression process modeling", International Journal of Refrigeration, 25(6), pp731-750, 2002.

[12] X. Luo, J. Wang, L. Shpanin, N. Jia, G. Liu, and A. Zinober, "Development of a mathematical model for vane-type air motors with arbitrary N vanes", in Proc. of World Congress on Engineering, 2008.

[13] J. Wang, X. Luo, L. Yang, L. Shpanin, N. Jia, S. Mangan, and J.W. Derby, "Mathematical modelling study of scroll air motors and energy efficiency analysis - Part II", IEEE/ASME Trans. on Mechatronics, Vol. 16, pp. 122-132, 2011.

[14] A. E. Fitzgerald, C. Kingsley, and D. U. Stephen, Electric machinery, 5th ed., Singapore, pp. 254-272, 1992.

[15] S.J. Chapman, Electric machinery fundamentals, 4th ed., McGraw-Hill, pp. 267-289, 2005.

[16] A. Zentai, and T. Daboczi, "Model based torque Estimation of permanent magnet synchronous machines", in IEEE International Symposium on Electric Machines, Power Electronics and Drives, Cracow, 2007.

[17] (2009) Mathworks, Matlab software user help files on Simpowersystem. [Online]. Available: http://www.mathworks.com/ help/toolbox/physmod/powersys/ref/permanentmagnetsynchronousmachine.html.

[18] (2008) Specification of M4-200X dc servomotor, Callan technology. [Online]. Available: http://www.callantechnology.com/callan_ technology_products/M4-200X/M4-200X.html.

[19] (2008) Handbook of AC synchronous brushless servomotors series EKM, Motor Technology. [Online]. Available:

http://www.motec.co.uk/euroServo/documents/es_ekm_m.pdf. 
[20] J. L. Wei, J. Wang, Q. H. Wu, "Development of a multi-segment coal mill model using an evolutionary computation technique", IEEE Transactions on Energy Conversion, Vol. 22. pp. 718-727, 2007.

[21] W. L. Kam, Applied Thermodynamics: Availability Method and Energy Conversion, Taylor \& Francis, pp.10-45, 1995.

[22] M.L. Cai, and T. Kagawa, "Energy consumption assessment of pneumatic actuating systems including compressor", IMechE, pp381380, C591/03302001, 2001.

[23] T. Eastop, and A. McConkey, Applied Thermodynamics for Engineering Technologists, Singapore: Longman, pp12-67, 1993.

[24] K.W. Li, Applied Thermodynamics: Availability Method and Energy Conversion, London: Taylor \& Francis, pp. 22-60, 1995.

[25] X., Luo, H., Sun, and J., Wang, An Energy Efficient Pneumatic-electrical System and Control Strategy Development, in Proc. of American Control Conference, San Francisco, U.S.A., 2011.

Xing Luo received his B.Eng. degree from Xi'an University of Technology, China, in 2004, the M.Sc. degree from the University of Liverpool, U.K., in 2006, and his Ph.D. degree from the University of Birmingham, U.K. in 2010. Currently, he is a Research Fellow with the School of Engineering, the University of Warwick, UK. His research interests include engine and pneumatic system, energy efficient systems, power electronic systems, real-time control strategy development.

Jihong Wang received her B.Eng. degree from Wuhan University of Technology, China, in 1982. She received the M.Sc. degree from Shandong University of Science and Technology, China, in 1985 and the PhD degree from Coventry University, U.K. in 1995. Currently, she is a Professor with the School of Engineering, the University of Warwick, UK. Her main research interests include nonlinear system control, system modelling and identification, power systems, energy efficient systems and applications of intelligent algorithms.

Hao Sun received the B.Eng. degree from Qingdao University, China, in 2008. He is currently working towards Ph.D. degree in School of Electronic, Electrical and Computer Engineering, University of Birmingham, U.K. His research interests include the pneumatic systems, power electronic systems, hybrid power train mechanism, and hardware-in-the-loop simulation. 